\title{
Phage display-derived ligands provide structural insight into insulin-like growth factor I function
}

\author{
Nicholas J. Skelton *, Michelle L. Schaffer, Kurt Deshayes, Tamas Blandl, Steven Runyon, \\ Gerald Nakamura and Sachdev S. Sidhu \\ Department of Protein Engineering, Genentech Inc., 1 DNA Way, South San Francisco, CA 94080, USA
}

\begin{abstract}
Insulin-like growth factor-I (IGF-I) is a central mediator of cell growth, differentiation and metabolism. Structural characterization of the protein has been hampered by a combination of internal dynamics and self-association that prevent crystallization and produce broad NMR resonances. To better characterize the functions of IGF-I, we have used phage display to identify peptides that antagonize the binding of IGF-I to its plasma binding proteins (IGFBPs) and cell-surface receptor (IGF-R). Interestingly, binding of peptide improves dramatically the quality of the NMR resonances of IGF-I, and enables the use of triple-resonance NMR methods to characterize the complexes. One such peptide, designated IGF-F1-1, has been studied in detail. In the complex, the peptide retains the same loop-helix motif seen in the free state whilst IGF-I contains three helices, as has been seen previously in low-resolution structures in the absence of ligand. The peptide binds at a hydrophobic patch between helix 1 and 3, a site identified previously by mutagenesis as a contact site for IGFBP1. Thus, antagonism of IGFBP1 binding exhibited by the peptide occurs by a simple steric occlusion mechanism. Antagonism of IGF-R binding may also be explained by a similar mechanism if receptor binding occurs by a two-site process, as has been postulated for insulin binding to its receptor. Comparisons with crystallographic structures determined for IGF-I in other complexes suggest that the region around helix 1 of IGF-I is conformationally conserved whereas the region around helix 3 adopts several different ligand-induced conformations. The ligand-induced structural variability of helix 3 appears to be a common feature across the insulin superfamily. In the case of IGF-I, exchange between such conformations may be the source of the dynamic nature of free IGF-I, and likely has functional significance for the ability of IGF-I to recognize two signaling receptors and six binding proteins with high affinity.
\end{abstract}

\section{Introduction}

Insulin-like growth factor-I (IGF-I) belongs to the insulin super-family of growth factors that control glucose metabolism, cell growth and embryonic development. The activities of IGF-I are more relevant in growth regulation and development than metabolic control, thus complementing the functions of insulin itself [12]. Insulin and IGF are usually resident in the serum and exert their biological activity by initiating a complex intracellular signal cascade on association with cell surface $\alpha_{2} \beta_{2}$ heterotetrameric receptors IGF-R and I-R [13]. IGF-I is further regulated by its association with one of six serum IGF binding proteins (IGFBP1-6; [2]) that sequester IGF in a high affinity complex, in some cases involving a third protein (the acid labile subunit or ALS) [3].

Members of the insulin super-family are all produced as single polypeptide chains containing three intra-chain disulfide bonds although in the case of insulin the central "C-region" is excised proteolyti-

\footnotetext{
${ }^{*}$ Corresponding author. Tel.: +1 650225 6402; Fax: +1 650225 3734; E-mail: skelly@ gene.com.
} 
cally to produce a disulfide-linked two-chain mature protein of 52 residues. In spite of their small size, characterization of the solution-conformation of IGF-I and insulin has been surprisingly difficult due to a combination of self-association and internal dynamics giving rise to many broad NMR resonances (e.g., see [10,20,29], [24]). In the case of insulin, crystallography has provided a high-resolution view of the protein under a variety of conditions (e.g., see $[1,5,6,16,18]$ ), while the use of organic solvents and mutagenesis have permitted a detailed description of its conformation in solution $[21,24,26]$. Until recently, structural studies on IGF-I have been of only low precision [10,14,23,29] limiting our ability to understand the structural differences between IGF-I and insulin that give rise to the specificity of receptor binding and hence their particular biological activities.

In order to learn more about this important signaling pathway, we have used phage display to obtain specific peptide ligands that antagonize the interactions between its component proteins [17,34]. An optimized phage selection approach was used to identify several families of peptides that bind to IGF-I [17]. Interestingly, the NMR spectrum of IGF-I is dramatically improved in the presence of several of these peptides. The present work describes one such peptide, designated IGF-F1-1, in detail. IGF-F1-1 binds to IGF-I with low micromolar affinity, has a well-defined structure by itself in solution, and is able to block both binding protein association and receptor signaling [17]. NMR spectroscopy has been used to characterize the complex between IGF-I and the peptide IGF-F1-1. The resulting structure provides insight into the interactions of IGF-I with its receptor and binding proteins. Comparison to the conformation adopted by IGF-I in several other complex structures determined recently suggests a cause for the dynamic behavior of IGF-I, behavior that we hypothesize is important for the recognition of six binding proteins and 3 cell-surface receptors by IGF-I.

\section{Materials and methods}

\subsection{Peptide synthesis}

Peptides were synthesized using standard 9-fluorenylmethoxycarbonyl (Fmoc) protocols, cleaved off the resin with $2.5 \%$ triisopropylsilane and $2.5 \% \mathrm{H}_{2} \mathrm{O}$ in trifluoroacetic acid (TFA), and purified by HPLC, as described previously [17]. The purity and mass of each peptide were verified by liquid chromatography/mass spectrometry (LC/MS).

\subsection{IGF-I production}

Labeled protein was obtained by from Esherichia coli 43E7 cells transformed with the IGF-Iexpressing vector utilizing an alkaline phosphatase promoter, as described previously $[19,28,31,35]$. The protein purity and integrity were verified by analytical HPLC, SDS-PAGE gel and by mass spectrometry.

\subsection{NMR spectroscopy}

NMR spectra of free peptides were acquired as described previously on a Bruker Avance-500 spectrometer using samples containing 1-5 mM peptide in $92 \% \mathrm{H}_{2} \mathrm{O} / 8 \% \mathrm{D}_{2} \mathrm{O} \mathrm{pH} 5.0-5.3$ and $30^{\circ} \mathrm{C}$. NMR spectra of peptides in complex with IGF-I were acquired at $40^{\circ} \mathrm{C}$ on Bruker Avance-600 or Avance-800 spectrometers. Complex samples contained $\sim 1.4 \mathrm{mM}$ protein and $\sim 2.0 \mathrm{mM}$ peptide in $25 \mathrm{mM} \mathrm{d}_{3}$-acetate buffer pH 5.1 at $40{ }^{\circ} \mathrm{C}$. Standard ${ }^{1} \mathrm{H},{ }^{1} \mathrm{H} /{ }^{15} \mathrm{~N}$ and ${ }^{1} \mathrm{H} /{ }^{15} \mathrm{~N} /{ }^{13} \mathrm{C}$ spectra were acquired as described by Cavanagh et al. [8] modified to include pulse field gradients. All analysis of NMR data was performed with 
the program FELIX (Accelrys, San Diego). Resonance assignments were made by standard methods using $2 \mathrm{D}{ }^{1} \mathrm{H}$ spectra in $\mathrm{H}_{2} \mathrm{O}$ for free peptides [39] or 3D triple resonance spectra for IGF-I in complex with the peptides [8].

\subsection{Structure calculations}

Structures of free peptides were determined as described [17]; the coordinates for IGF-F1-1 were deposited with the Protein Data Bank (accession number 1LB7). Distance restraints for IGF-I in complex with the peptide were obtained from analysis of the following NOESY spectra acquired at $800 \mathrm{MHz}$ : $3 \mathrm{D}{ }^{1} \mathrm{H}^{-15} \mathrm{~N}$ NOESY-HSQC, 2D ${ }^{14} \mathrm{~N}$-filtered ${ }^{1} \mathrm{H}$ NOESY, 3D ${ }^{13} \mathrm{C}$-edited NOESY and 2D ${ }^{12} \mathrm{C}$-filtered ${ }^{1} \mathrm{H}$ NOESY. Intermolecular interactions were identified unambiguously in a $3 \mathrm{D} \omega_{1}{ }^{12} \mathrm{C}$-filtered, $\omega_{2}{ }^{-13} \mathrm{C}-$ edited NOESY spectrum. Dihedral angle restraints were obtained from analysis of $3 \mathrm{D}{ }^{15} \mathrm{~N}-{ }^{1} \mathrm{H}$ HNHA $(\phi), 3 \mathrm{D}{ }^{15} \mathrm{~N}-{ }^{1} \mathrm{H}$ HNHB and $3 \mathrm{D}{ }^{15} \mathrm{~N}-{ }^{1} \mathrm{H}$ TOCSY-HSQC $\left(\chi_{1}\right)$ spectra. Additional conservative backbone dihedral angle restraints were obtained from analysis of backbone chemical shifts with the program TALOS [11]. Restraints for 12 hydrogen bonds were imposed within the helices $(8,2$ and 2 in helices 1,2 and 3, respectively) on the basis of slow amide proton exchange with solvent. Structures were calculated using the program CNX (v2000.1; Accelrys, San Diego). 100 structures were calculated using torsion angle dynamics followed by Cartesian dynamics and minimization. The 20 structures of lowest restraint violation energy were chosen to represent the solution structure of the IGF-I in complex with IGF-F1-1 and were deposited with the Protein Data Bank (accession number 1PMX). More details can be found in Schaffer et al. [31].

\section{NMR spectra of uncomplexed IGF-I}

Previous researchers have demonstrated that the NMR spectra of IGF-I by itself are of poor quality. This has been attributed to a combination of self-association and also internal dynamics leading to a range of line widths for the NMR resonances [10,29]. Moreover, the line widths are $\mathrm{pH}-$, temperatureand concentration-dependent. Structural studies have relied on the use of low $\mathrm{pH}$ or organic acid cosolvents (e.g., 20\% acetic acid) to optimize the spectrum [10,23,29]. The spectra shown in Fig. 1 obtained for $\sim 1 \mathrm{mM}$ IGF-I at pH 5.0 and $40^{\circ} \mathrm{C}$ exemplify the problem, with the ${ }^{1} \mathrm{H}$ NOESY containing broad streaks instead of resolved peaks, and the ${ }^{1} \mathrm{H}^{-15} \mathrm{~N}$ HSQC containing only $\sim 18$ sharp, well resolved peaks and another 12 broad weak peaks. 64 backbone amide and six side chain amide peaks are expected.

\section{Stream-lined phage display generation of peptide ligands}

Phage display has proven to be a useful tool for generating peptide ligands to proteins of biological or pharmaceutical interest (e.g., see [32,33]). We have recently described a streamlined process for the generation of such ligands, using IGF-I as the test case [17]. Throughout this process, 96-well plate formats are used to facilitate automation and high throughput. An initial search is made using a very diverse library ( $\sim 10^{23}$ potential sequences) based on 22 disulfide-containing scaffolds that is only sparsely populated $\left(\sim 10^{11}\right.$ actual sequences). During the initial rounds of selection and amplification, polyvalent display allows avidity to enhance the selection of weakly binding sequences. The selection process is terminated once the majority of the selected phage are positive for binding to IGF-I in a competition ELISA assay. DNA sequencing is then applied to several hundred of the positive clones to identify the 


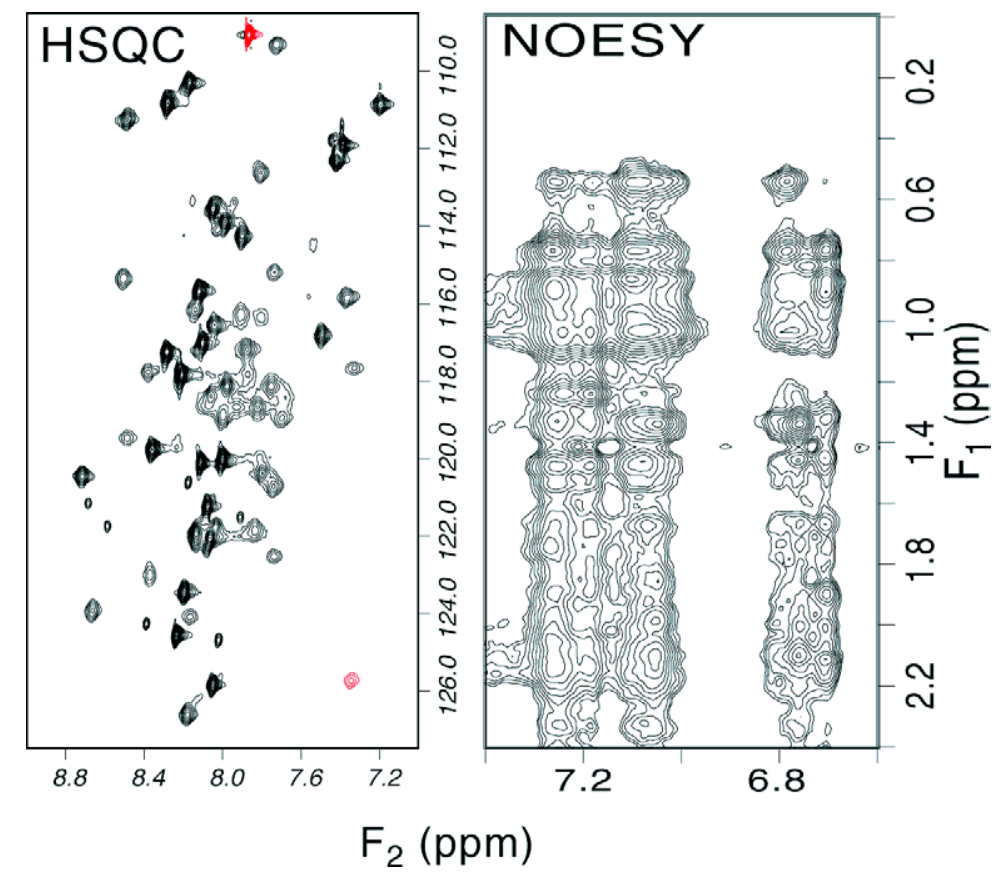

Fig. 1. NMR spectra of IGF-I at pH 5.0 and $40{ }^{\circ} \mathrm{C}(\sim 1 \mathrm{mM}$ concentration $)$; at left is a portion of the ${ }^{1} \mathrm{H}_{-}{ }^{15} \mathrm{~N}$ HSQC and at right a portion of the ${ }^{1} \mathrm{H} \operatorname{NOESY}\left(\tau_{m}=100 \mathrm{~ms}\right)$. Both spectra were recorded at $600 \mathrm{MHz}$.

consensus sequences of scaffolds that are able to bind. Secondary libraries are then prepared that contain a variety of tailored codons to span the sequence diversity observed within the consensus sequence for each scaffold. These secondary libraries are designed to have a low total diversity so that complete coverage can be obtained experimentally. Several rounds of selection from this second library are performed in a monovalent fashion so that more stringent binding criteria can be applied, thereby selecting preferentially for the tightest binding sequences. After DNA sequencing of positive clones, representative peptide sequences are chosen for chemical synthesis and further biophysical and biochemical characterization.

When IGF-I was used as the target in such a process, the initial selection identified six unique scaffolds capable of binding. Secondary libraries were prepared for one of these scaffolds: $\mathrm{X}_{2} \mathrm{CX}_{9} \mathrm{CX}_{2} \mathrm{G}$, where $\mathrm{X}$ represent the randomized residues flanking and between a fixed pair of cysteine residues. Selection from this library gave rise to several related sequences one of which was synthesized (IGF-F1-1: RNCFESFVAALRRCMYG). The synthetic 16-residue peptide was able to bind to IGF-I and antagonize the interaction with IGFBP-1 $\left(I C_{50} 1.4 \mu \mathrm{M}\right)$, IGFBP-3 $\left(I C_{50} 3 \mu \mathrm{M}\right)$ IGF-R $\left(I C_{50} 5 \mu \mathrm{M}\right)$ and I-R $\left(I C_{50} 6 \mu \mathrm{M}\right)$. For comparison, one of the intermediate sequences obtained after the polyvalent selection process was also synthesized (IGF-F1-parent: DECLMSVEALKNCMGG). The binding of this peptide was poor and lead to only weak $\left(I C_{50} \sim 200 \mu \mathrm{M}\right)$ or undetectable $\left(I C_{50}>750 \mu \mathrm{M}\right)$ inhibition of binding to the receptors and binding proteins described above demonstrating the improvement in affinity obtained in the maturation process [17].

The synthetic peptides IGF-F1-parent and IGF-F1-1 were also characterized by NMR spectroscopy. The dispersion of peaks in the fingerprint region of the 2QF-COSY spectrum suggests a greater degree of folding in the fully optimized peptide: residues at the N-terminus of IGF-F1-1 have $\mathrm{H}^{\mathrm{N}}$ shifts far removed from random coil values whereas residues in the $\mathrm{C}$-terminal half of the peptide have consistent 


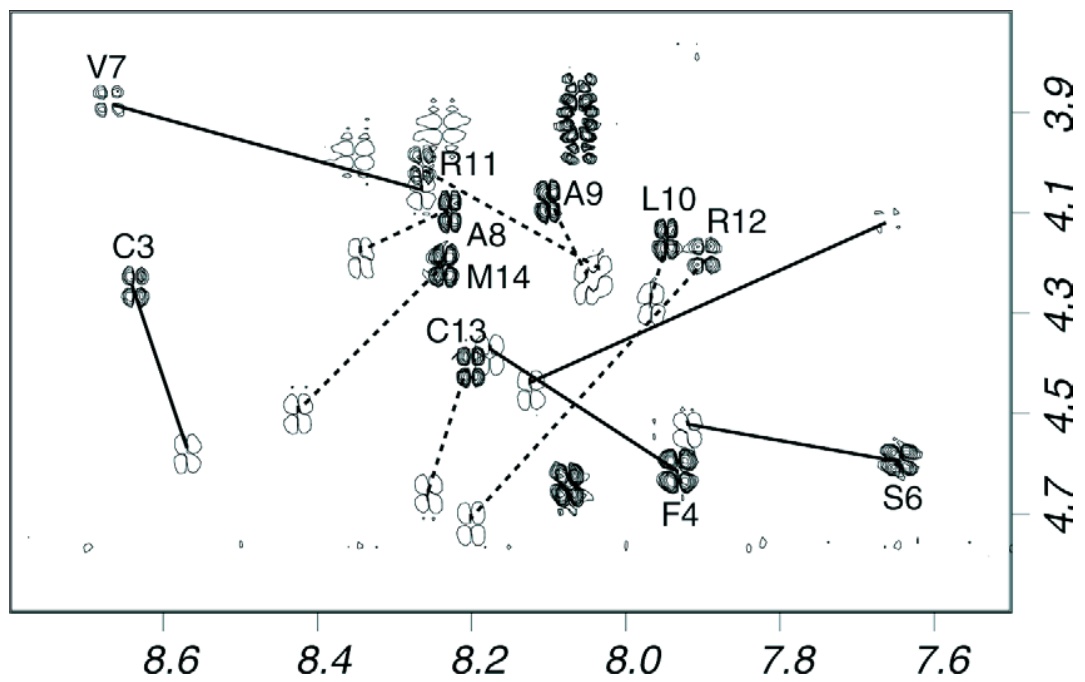

Fig. 2. Finger print region of the 2QF-COSY spectrum of IGF-F1-parent (single contour) and IGF-F1-1 (multiple contours). Solid lines connect the peaks at the N-termini of the two peptides (the N-terminal turn region) whilst the dotted lines connect the peaks in the C-terminal portion of the peptide (the helix). Both spectra were acquired at $30^{\circ} \mathrm{C}$ at $500 \mathrm{MHz}$.
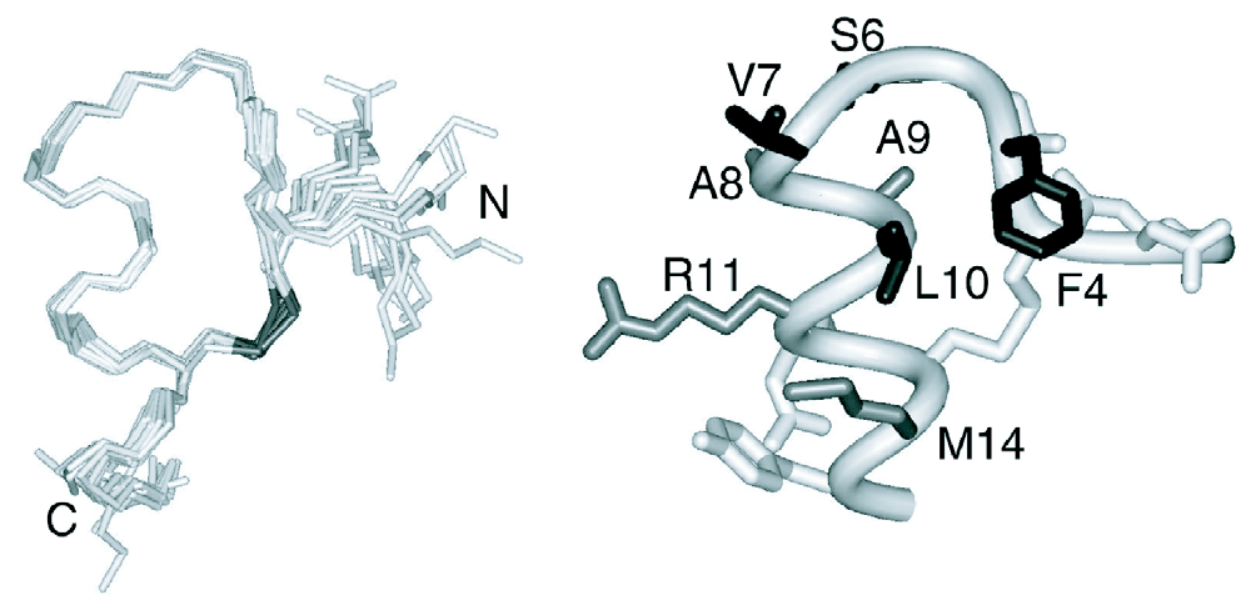

Fig. 3. The structure of IGF-F1-1. At left is the ensemble of 20 structures, with the backbone atoms (white) and disulfide bond (grey) shown. At right a representative structure is shown with the side chains shaded black, grey or white depending on whether the side chain is very, moderately or not important for binding to IGF-I.

deviations of $\mathrm{H}^{\alpha}$ towards lower chemical shift. ${ }^{13} \mathrm{C}^{\alpha}$ and ${ }^{13} \mathrm{C}^{\beta}$ secondary chemical shifts (the difference between observed and random coil chemical shift values) are also much more extreme for IGF-F1-1 [17]. Presumably the rigidified structure offers an entropic benefit to binding. Further analysis of the NMR spectra of IGF-F1-1 generated 91 distance and 26 dihedral angle restraints that were used to define the structure of the peptide using distance geometry and restrained molecular dynamics simulations. The structure is comprised of an N-terminal loop and turn followed by a C-terminal helix; the disulfide bond connects the N-terminal loop to the C-terminal turn of the helix (Fig. 3). Several hydrophobic residues pack along one face of the peptide, a feature that has been utilized by other phage-derived peptides to contact their target proteins (e.g., see $[15,27,34]$ ). Phage-based alanine scanning mutagenesis 
techniques [38] indicate that substitution of these hydrophobic residues and an adjacent basic residue of IGF-F1-1 are deleterious to IGF-I-binding (Fig. 3) [31].

\section{NMR spectra of IGF-I in complex with phage peptides}

Surprisingly, formation of a complex with peptide IGF-F1-1 leads to a dramatic improvement in the quality of the NMR spectra of IGF-I. In addition to a general sharpening in the ${ }^{1} \mathrm{H}$ 1D spectrum, the ${ }^{1} \mathrm{H}$ NOESY spectrum now contains discrete, well-resolved cross peaks and over 60 backbone $\mathrm{NH}$ resonances can be readily identified in the $1 \mathrm{H}^{-15} \mathrm{~N}$ HSQC spectrum (Fig. 4). Clearly, formation of the complex decreases the tendency of IGF-I to self-associate and/or limits the internal mobility of the protein. The spectra were of such high quality that we prepared uniformly labeled ${ }^{15} \mathrm{~N} /{ }^{13} \mathrm{C}$ IGF-I to allow a complete structural characterization of the complex [31]. The backbone resonances of IGF-I in the complex were readily assigned from triple resonance NMR experiments acquired in $\mathrm{H}_{2} \mathrm{O}$ solution (e.g., $\mathrm{HNCA}, \mathrm{CBCA}(\mathrm{CO}) \mathrm{NH}, \mathrm{HBHA}(\mathrm{CBCACO}) \mathrm{NH}$; [8]) and side chain assignments were completed from an HCCH-TOCSY experiment acquired in $\mathrm{D}_{2} \mathrm{O}$ solution [8]. ${ }^{15} \mathrm{~N}$ - and ${ }^{13} \mathrm{C}$-filtered $2 \mathrm{D}{ }^{1} \mathrm{H}$ TOCSY and NOESY spectra were used to partially assign the peptide resonances.

In the bound state, a number of the peptide resonances were quite broad precluding complete assignments and generation of intra-peptide restraints. Thus, the 47 experimentally-derived intra-peptide restraints (all of which were fully consistent with the structure determined for IGF-F1-1 in the absence of IGF-I) were augmented with a number of loose backbone dihedral angle restraints to keep the backbone conformation of IGF-F1-1 close to that observed in solution. Distance restraints within IGF-I were

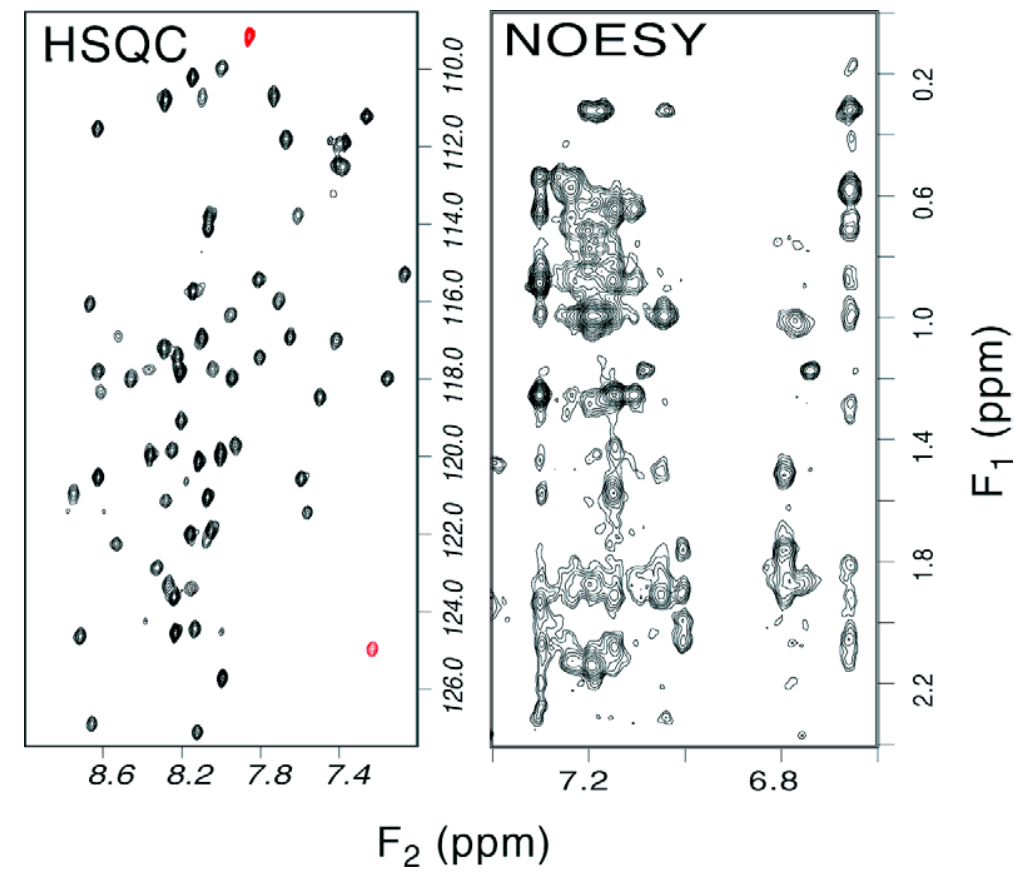

Fig. 4. NMR spectra of IGF-I in the presence of IGF-F1-1 at pH 5.0 and $40^{\circ} \mathrm{C}(\sim 1 \mathrm{mM}$ IGF-I); at left is a portion of the ${ }^{1} \mathrm{H}^{-15} \mathrm{~N}$ HSQC and a right a portion of the ${ }^{1} \mathrm{H}$ NOESY $\left(\tau_{m}=100 \mathrm{~ms}\right)$. Both spectra were recorded at $600 \mathrm{MHz}$ under conditions identical to the spectra shown in Fig. 1. 


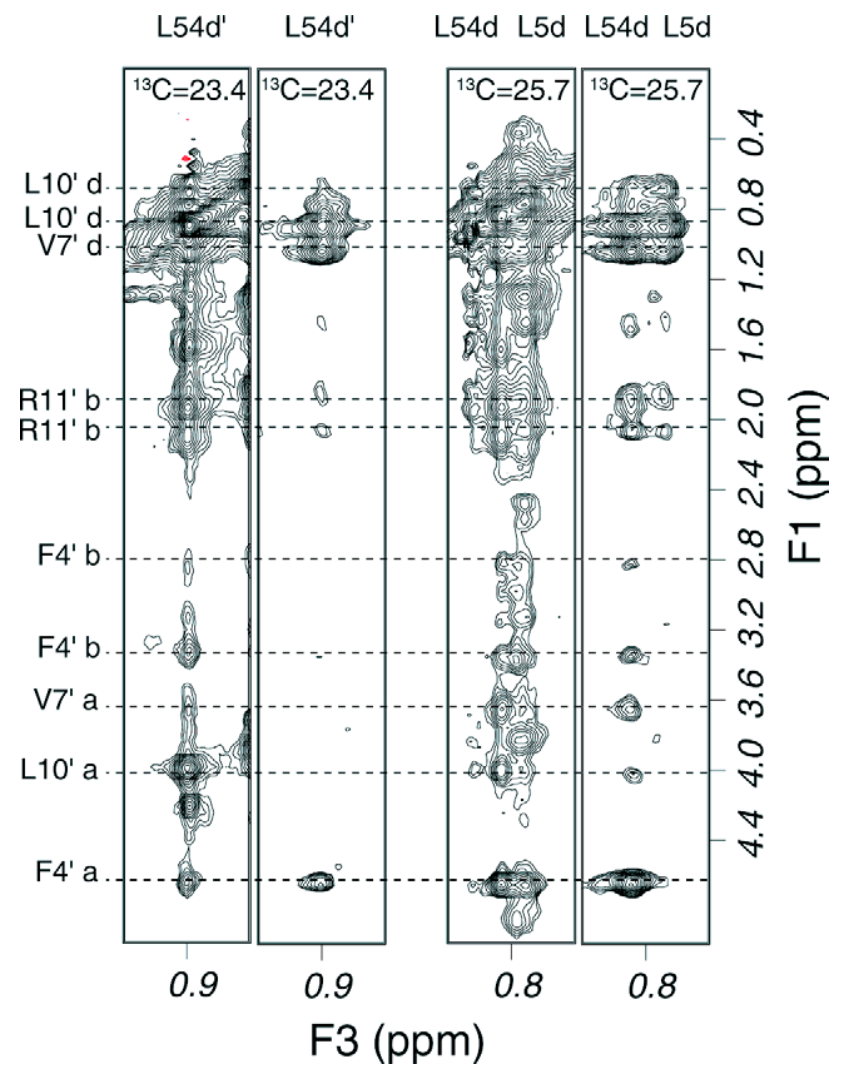

Fig. 5. Comparison of the 3D edited ${ }^{13} \mathrm{C}$ NOESY (left-hand strip in each pair) and the 3D $\omega_{1}-{ }^{12} \mathrm{C}$-filtered, $\omega_{2}-{ }^{13} \mathrm{C}$-edited NOESY (right-hand strip). Peaks from three methyl groups of IGF-I (Leu54 $\delta$, Leu54 $\delta^{\prime}$ and Leu5 $\delta$ ) to peptide resonances are labeled.

obtained from ${ }^{15} \mathrm{~N}$ - and ${ }^{13} \mathrm{C}$-edited NOESY spectra, both of which were of very high quality. Intermolecular NOE peaks were unambiguously identified in a 3D $\omega_{1}{ }^{12} \mathrm{C}$-filtered, $\omega_{2}{ }^{13} \mathrm{C}$-edited NOESY spectrum [41]. This experiment makes use of swept adiabatic pulses to filter out those protons attached to ${ }^{13} \mathrm{C}$ (i.e. those in IGF-I) leaving only the peptide-bound protons in the $\omega_{1}$ dimension. Following the NOESY mixing period, the ${ }^{1} \mathrm{H}$ and ${ }^{13} \mathrm{C}$ frequencies are measured for ${ }^{1} \mathrm{H}-{ }^{13} \mathrm{C}$ groups close in space to the original ${ }^{1} \mathrm{H}-{ }^{12} \mathrm{C}$ group. The clarification afforded by this scheme is shown in Fig. 5. In total 87 intermolecular distance restraints were identified in this spectrum. Over 800 other distance restraints derived from the other NOESY spectra were combined with $139 \phi, \psi$, and $\chi 1$ dihedral angle restraints and used as input for the determination of structures using a torsion-angle dynamics protocol [31].

The NMR restraints define with high precision the location of three helices in addition to extended strands on either side of the N-terminal helix and the loop between the second and third helices (Fig. 6). The restraints do not define a conformation for residues 28 to 41 (the "C-loop") or the C-terminus (the "D-region"). The secondary structure elements are reminiscent of the low-resolution IGF-I structures $[10,14,23,29]$, and are also very similar to the structure of insulin $[1,5,6,16,18]$. The loop-helix conformation of IGF-F1-1 is preserved in the complex, and the hydrophobic helical surface contacts IGF-I, as suggested by the alanine-scanning mutagenesis (Fig. 3). In particular, Phe3, Val7 and Leu10 of the peptide "pinch" Leu54 of IGF-I. An outer ring of hydrophobic or basic residues from IGF-I make additional contacts with the peptide (Fig. 6). 


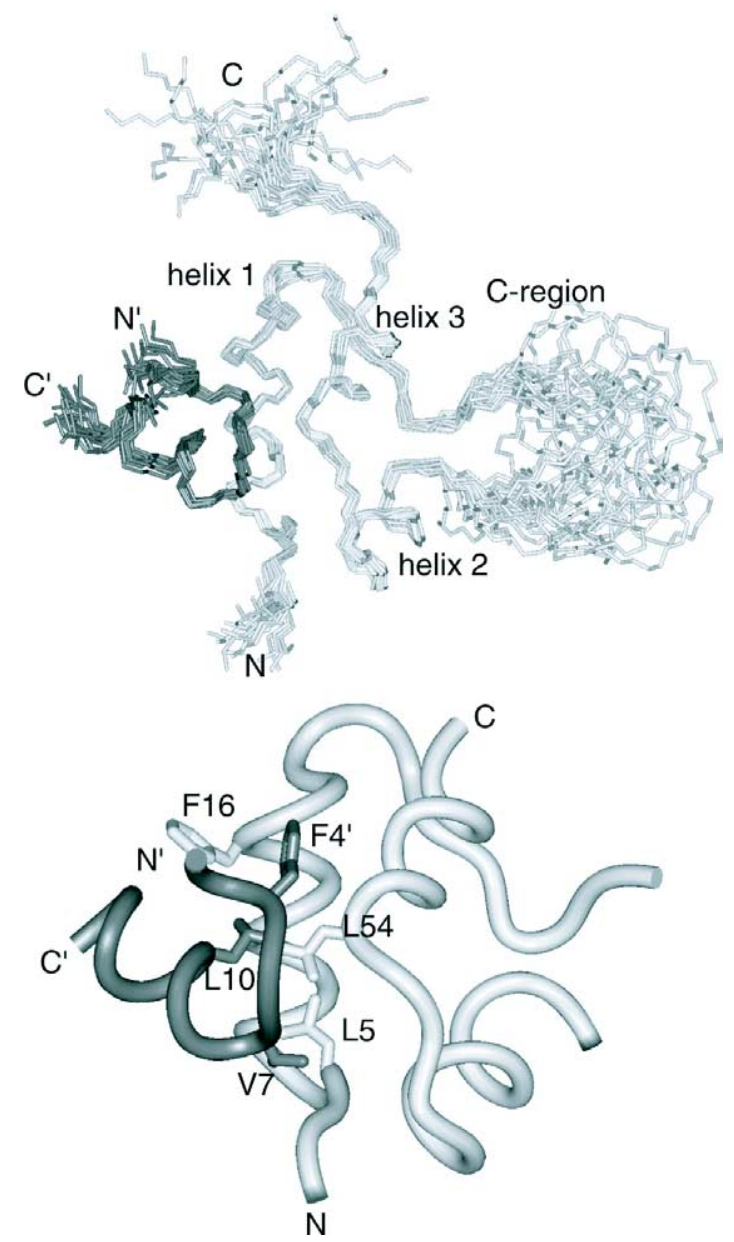

Fig. 6. Ensemble of 20 structures determined for IGF-I (white) when bound to IGF-F1-1 (grey); all backbone heavy atoms are shown. At bottom is a representative structure of the complex highlighting some of the hydrophobic contacts between the protein and peptide; residues 29-41 and 64-70 are omitted from the backbone tube for clarity.

\section{IGF-I in complex with other molecules}

During the course of these studies, three high quality structures have been determined for IGF-I by crystallographic methods $[7,37,40]$. In all three cases, the structure for IGF-I could only be obtained in the presence of a ligand; the detergents deoxy big CHAPS and SB12 were used in two of the complexes whilst the third involved a fragment of IGFBP5 (miniIGFBP5). The finding that high-quality structural data for IGF-I can only be obtained in the presence of a ligand suggests that physical properties of the free protein that prevent structural analysis are ameliorated in the presence of ligand.

The three helices of IGF-I are present in all of the complexes. Structural superposition indicates that the helix 1 and the succeeding extended strand is the most structurally homogeneous region of IGF-I, with the same helix-strand packing observed in all complexes. Indeed, this arrangement is also seen for IGF-II [36], insulin [16] and other members of the super-family (Fig. 7) [31]. Another common feature is that the same hydrophobic patch between helix 1 and 3 on IGF-I is always used to interact with the ligand. For both detergent complexes, the lipophilic portion of the detergent contacts this surface. 

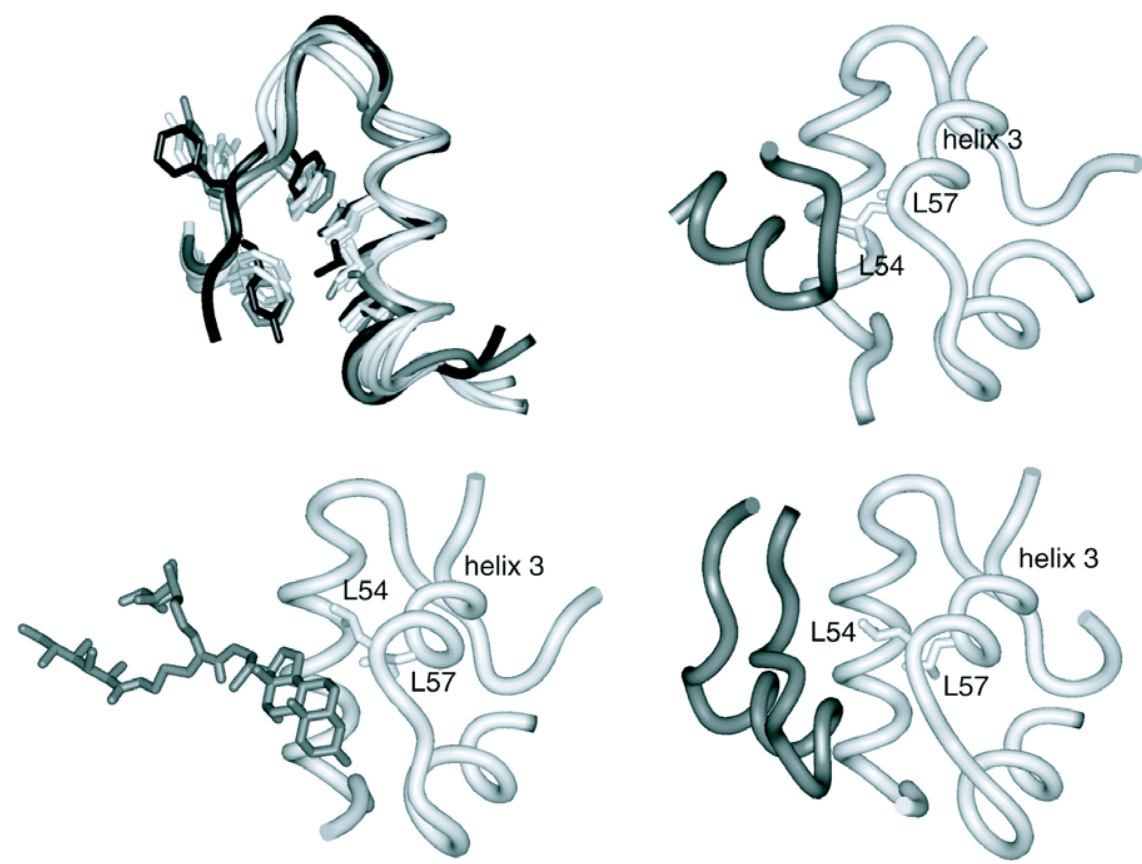

Fig. 7. Structural comparisons to the IGF-F1-1 complex. The conserved packing between the N-terminal helix and strand for several insulin super-family proteins is shown at top left (four IGF-I structures, white; IGF-II, grey; insulin, black). Ligand-induced variation of helix 3 is shown for IGF-I in complex with IGF-F1-1 (top right), deoxy bigCHAPS (lower left) and miniIGFBP5 (lower right). In all cases, IGF-I is white and the ligands are grey. The backbone of miniIGFBP5 is only shown for residues 59 to 81 .

Interestingly, miniIGFBP5 uses a hydrophobic helix to interact with the patch on IGF-I in a fashion that is similar to IGF-F1-1 binding. However, the exact conformation of helix 3 and its orientation with respect to helix 1 does vary, presumably in response to the particular shape of the ligand (Fig. 7). This leads to very different orientations for Leu54 and Leu57 in the miniIGFBP5, detergent and peptide complexes (Fig. 7). The observation of structural heterogeneity for helix 3 suggests that its motion in the absence of ligand might be the cause of the dynamic nature of IGF-I. Presumably, association with ligand reduces this flexibility and "freezes out" helix 3 into a particular conformation that is ligand-dependent.

\section{NMR characterization of other complexes}

We have recently begun to characterize the interaction between IGF-I and several other peptides resulting from our phage display experiments. Peptide IGF-P3 and IGF-P6 are very different in sequence from each other and from IGF-F1-1 yet are also able to bind to IGF-I with affinities in the low micromolar range. Although IGF-P3 and IGF-P6 both contain a single disulfide bond, the former appears to be completely unstructured in solution whilst the later adopts a helix-loop structure that is much less well-defined than the conformation of IGF-F1-1 by itself. In spite of the range of conformational flexibility observed for the free peptides, all three are able to bind to IGF-I with low micromolar affinities and all three induce similar improvements in the quality of the NMR spectra of IGF-I (Fig. 8). Complete NMR analysis of the IGF-P3 and IGF-P6 complexes are underway to determine the structures induced in the peptides by IGF-binding, and also to ascertain how IGF-I is able to recognize these three very 

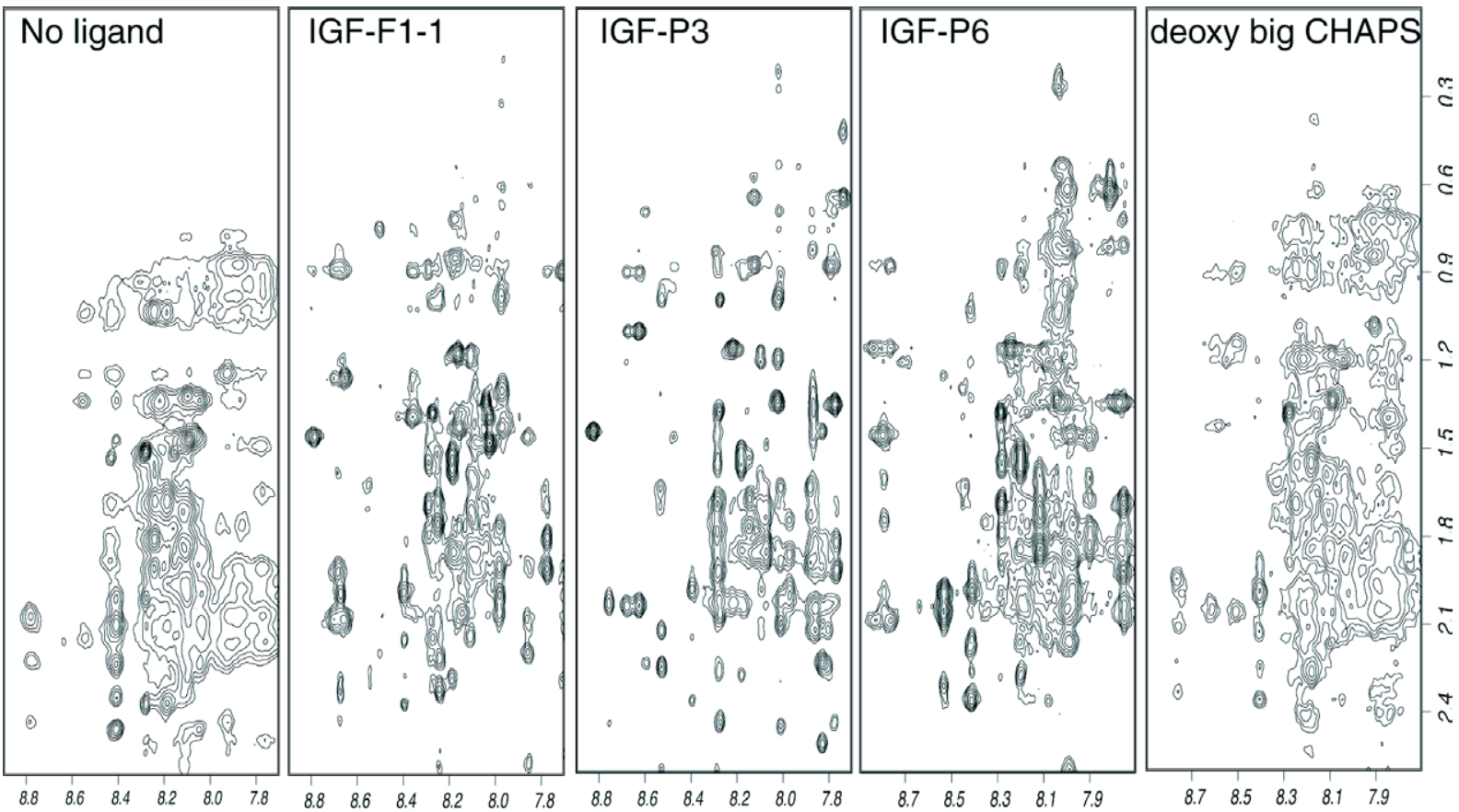

Fig. 8. $\mathrm{H}^{\mathrm{N}}-\mathrm{H}^{\text {aliphatic }}$ region of the NOESY spectra $\left(\tau_{m}=100 \mathrm{~ms}\right)$ for IGF-I by itself or when bound to IGF-F1-1, IGF-P3, IGF-P6 or deoxy big CHAPS. All spectra were acquired with $1 \mathrm{mM}$ protein at $40^{\circ} \mathrm{C}, \mathrm{pH} 5.1$. The deoxy big CHAPS spectrum was acquired at $500 \mathrm{MHz}$, all others were at $600 \mathrm{MHz}$.

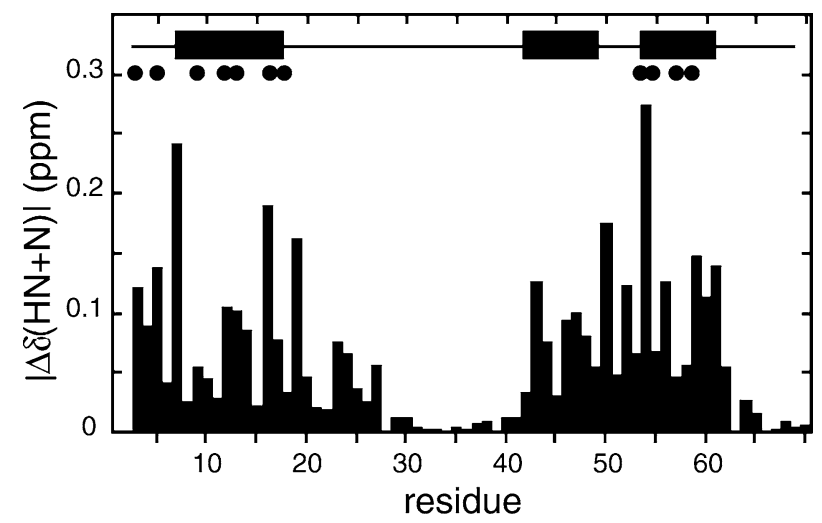

Fig. 9. Summary of differences in ${ }^{1} \mathrm{H}^{\mathrm{N}}$ and ${ }^{15} \mathrm{~N}$ chemical shifts of IGF-I between the IGF-F1-1 and IGF-P 3 complexes. The absolute values of the sum of shift differences are shown $\left({ }^{15} \mathrm{~N}\right.$ shifts weighted by 0.17 to account for the wider spectral width of ${ }^{15} \mathrm{~N}$ ). The boxes above the plot indicate the three helices, while the circles indicate those residues that contact peptide in the IGF-F1-1 complex.

different sequences. Preliminary data for the IGF-P3 complex suggest that it too is binding to the surface patch between helix 1 and helix 3. However, the pattern of IGF-I chemical shifts is not identical to the IGF-F1-1 case suggesting that there may be a subtle difference in the region of the helix 1/helix 3 patch utilized for association, or a slight change in the conformation of IGF-I induced by each peptide (Fig. 9). 
The complex formed between IGF-I and deoxy big CHAPS has also been analyzed by NMR. Diffusion measurements were used to estimate an affinity between these two molecules of $\sim 200 \mu \mathrm{M}$ [37]. However, binding to IGF-I does not improve the quality of the NMR resonances of IGF-I (Fig. 8). This suggests that detergent binding by itself is not able to completely reduce the internal dynamics of IGF-I in solution. However, detergent binding does offer sufficient stabilization of IGF-I to promote the formation of a stable crystalline lattice, and once in the crystalline environment, only a single dominant conformation is observed for the helical core.

\section{Biological consequences}

The observed binding site for IGF-F1-1 on IGF-I provides a ready explanation for the peptide's ability to antagonize the interaction with IGFBP1 and IGFBP3. Numerous mutagenesis studies have demonstrated that residues near the N-terminus of IGF-I and residues in helix 1 form the principle interaction surface for the IGF-binding proteins (e.g., see $[9,19,25]$ ), and this is exactly where IGF-F1-1 binds. Explaining the antagonism of receptor binding is less clear cut as the long-established receptor binding site on IGF-I involves residues in the extended strand following helix 1 and several residues in the Cloop [4]. However, in the case of insulin a "second site" of receptor contact [12,30] has been proposed to involve residues corresponding to Phe16 and Leu54 of IGF-I. Such a model is validated by at least one mutagenesis report wherein replacement of Phe16 with alanine did reduce binding to IGF-R [22]. Thus, the antagonism of IGF-F1-1 towards IGF-R may be explained by steric occlusion of the second site [31].

On the basis of the structural comparisons noted above, we speculate that the dynamic nature of the insulin super-family results from motions within helix 3 and also motions of helix 3 with respect to the structurally conserved N-terminal sub-domain (Fig. 7). In the case of IGF-I, the relative motions of helix 3 are most likely responsible for the poor quality of NMR spectra in the absence of ligand. Moreover, we hypothesize that the malleability of the binding site is functionally important since it allows IGF-I to recognize several cell-surface receptors and six serum binding proteins, in addition to non-physiological interactions with several classes of peptide and detergent.

\section{Acknowledgements}

We thank Drs. Wayne Fairbrother and Borlan Pan for assistance with the acquisition of NMR spectra. Drs. Henry Lowman, Felix Vajdos, Mark Ultsch, Samantha Lien, Tim Stewart, and Ron Siddell are thanked for many fruitful discussions during the course of this work.

\section{References}

[1] E. Baker, T. Blundell, J. Cutfield, S. Cutfield, E.J. Dodson, G. Dodson, D. Hodgkin, R.E. Hubbard, N. Isaacs and C. Reynolds, The structure of $2 Z n$ pig insulin at $1.5 \AA$ resolution, Philos. Trans. R. Soc. Lond. B 319 (1988), 369-456.

[2] F.J. Ballard, R.C. Baxter, M. Binoux, D.R. Clemmons, S. Drop, K. Hall, R. Hintz, M. Rechler, E. Rutanen and J. Schwander, On the nomenclature of the IGF binding proteins, Acta Endocrinol. 121 (1989), 751-752.

[3] R.C. Baxter and J. Martin, Binding proteins for the insulin-like growth factors: structure, regulation and function, Prog. Growth Factor Res. 1 (1989), 49-68.

[4] M.L. Bayne, J. Applebaum, G.G. Chicci, R.E. Miller and M.A. Cascieri, The roles of tyrosines 24, 31 abd 60 in the high affinity binding of insulin-like growth factor to the type 1 IGF receptor, J. Biol. Chem. 265 (1990), 15648-15652. 
[5] T.L. Blundell, G.G. Dodson, D. Hodgkin and D. Mercola, Adv. Protein Chem. 26 (1972), 279-402.

[6] J. Brange, U. Ribel, J.F. Hansen, G.G. Dodson, M.T. Hansen, S. Havelund, S.G. Melberg, F. Norris, K. Norris, L. Snel, A.R. Sørensen and H.O. Voigt, Monomeric insulins obtained by protein engineering and their medical implications, Nature 333 (1988), 679-682.

[7] A.M. Brzozowski, E.J. Dodson, G.G. Dodson, G.N. Murshudov, C. Verma, J.P. Turkenberg, F.M. de Bree and Z. Dauter, Structural origin of the functional divergence of human insulin-like growth factor-I and insulin, Biochemistry 41 (2002), 9389-9397.

[8] J. Cavanagh, W.J. Fairbrother, A.G. Palmer and N.J. Skelton, Protein NMR Spectroscopy, Principles and Practice, Academic Press, New York, 1995.

[9] D.R. Clemmons, M.L. Dehoff, W.H. Busby, M.L. Bayne and M.A. Cascieri, Competition for binding to insulin-like growth factor binding protein-2, 3, 4 and 5 by the IGFs and IGF analogs, Endocrinology 131 (1992), 890-895.

[10] R.M. Cooke, T.S. Harvey and I.D. Campbell, Solution structure of IGF-1: a NMR and restrained molecular dynamics study, Biochemistry 30 (1991), 5484-5491.

[11] G. Cornilescu, F. Delaglio and A. Bax, Protein backbone dihedral angle restraints from searching a database for chemical shift and sequence homology, J. Biomolec. NMR 13 (1999), 289-302.

[12] P. De Meyts, The structural basis of insulin and insulin-like growth factor-I receptor binding and negative co-operativity, and its relevance to mitogenic versus metabolic signalling, Diabetologia 37(Suppl. 2) (1994), S135-S148.

[13] P. De Meyts, B. Wallach, C.T. Christoffersen, B. Ursø, K. Grønskov, L.-J. Latus, F. Yakushiji, M.M. Ilondo and R.M. Shymko, The insulin-like growth factor receptor, Horm. Res. 42 (1994), 152-169.

[14] E. De Wolf, R. Gill, S. Geddes, J. Pitts, A. Wollmer and J. Grötzinger, Solution structure of mini-IGF-I, Protein Sci. 5 (1996), 2193-2202.

[15] M.S. Dennis, C. Eigenbrot, N.J. Skelton, M.H. Ultsch, L. Santell, M.A. Dwyer, M.P. O’Connell and R.A. Lazarus, Peptide exosite inhibitors of factor VIIa as anticoagulants, Nature 404 (2000), 465-470.

[16] U. Derewenda, Z. Derewenda, E.J. Dodson, G.G. Dodson, X. Bing and J. Markussen, X-ray analysis of the single chain B29-A1 peptide-linked insulin molecule. A completely inactive analogue, J. Mol. Biol. 220 (1991), 425-433.

[17] K. Deshayes, M.L. Schaffer, N.J. Skelton, G.R. Nakamura, S. Kadkhodayan and S.S. Sidhu, Rapid identification of small binding motifs with high-throughput phage display: discovery of peptidic antagonists of IGF-I function, Chemistry \& Biology 9 (2002), 495-506.

[18] E.J. Dodson, G.G. Dodson, R.E. Hubbard and C.D. Reynolds, Insulin's structural behavior and its relationship to activity, Biopolymers 22 (1983), 281-291.

[19] Y. Dubaquié and H.B. Lowman, Total alanine scanning mutagenesis of insulin-like growth factor I (IGF-I) identifies differential binding epitopes for IGFBP-1 and IGFBP-3, Biochemistry 38 (1999), 6386-6396.

[20] Q.-X. Hua, M. Kochoyan and M. Weiss, Structure and dynamics of a des-pentapeptide-insulin in solution: the molten globule hypothesis, Proc. Natl. Acad. Sci. USA 89 (1992), 2379-2383.

[21] Q.-X. Hua, S.E. Shoelson, M. Kochoyan and M. Weiss, Receptor binding redefined by a structural switch in a mutant human insulin, Nature 354 (1991), 238-241.

[22] M. Jansson, M. Uhlen and B. Nilsson, Structural changes in IGF-1 mutant proteins affecting binding kinetics to IGFBP-1 and IGF-I receptor, Biochemistry 36 (1997), 4108-4117.

[23] L.G. Laajoki, G.L. Francis, J.C. Wallace, J.A. Carver and M.A. Keniry, Solution structure and backbone dynamics of long-[Arg3] insulin-like growth factor, J. Biol. Chem. 275 (2000), 10009-10015.

[24] S. Ludvigsen, M. Roy, H. Thøgersen and N. Kaarsholm, High-resolution structure of an engineered biologically potent insulin monomer, B16Tyr-His, as determined by NMR spectroscopy, Biochemistry 33 (1994).

[25] B. Magee, G.K. Shooter, J.C. Wallace and G.L. Francis, Insulin-like growth factor I and its binding proteins: a study of the binding domain using B-domain analogs, Biochemistry 38 (1999), 15863-15870.

[26] H. Olsen, S. Ludvigsen and N. Kaarsholm, Solution structure of an engineered insulin monomer at neutral pH, Biochemistry 35 (1996), 8836-8845.

[27] B. Pan, B. Li, S.J. Russell, J.K. Tom, A.G. Cochran and W.J. Fairbrother, Solution structure of a phage-derived peptide antagonist in complex with vascular endothelial growth factor, J. Mol. Biol. 316 (2002), 769-787.

[28] D. Reilly and W.J. Fairbrother, A novel isotope labeling protocol for bacterially expressed proteins, J. Biomol. NMR 4 (1994), 459-462.

[29] A. Sato, S. Nishimura, T. Ohkubo, Y. Kyogoku, S. Koyama, M. Kobayashi, T. Yasuda and Y. Kobayashi, Threedimensional structure of human IGF-I determined by NMR and distance geometry, Int. J. Pept. Protein. Res. 41 (1993), 433-440.

[30] L. Schäffer, A model for insulin binding to the insulin receptor, Eur. J. Biochem. 227 (1994), 1127-1132.

[31] M.L. Schaffer, K. Deshayes, G.R. Nakamura, S.S. Sidhu and N.J. Skelton, Complex with a phage display-derived peptide provides insight into the function of insulin-like growth factor I, Biochemistry (2003), in press.

[32] S.S. Sidhu, Phage display in pharmaceutical biotechnology, Curr. Opin. Biotech. 11 (2000), 610-616. 
[33] S.S. Sidhu, W.J. Fairbrother and K. Deshayes, Exploring protein-protein interactions with phage display, Chem. Biochem. 4 (2003), 14-25.

[34] N.J. Skelton, Y.M. Chen, N. Dubree, C. Quan, D.Y. Jackson, A.G. Cochran, K. Zobel, K. Deshayes, M. Baca, M.T. Pisabarro and H.B. Lowman, Structure-function analysis of a phage-derived peptide that binds to IGFBP-1, Biochemistry 40 (2001), 8487-8498.

[35] J. Swartz, Method for producing polypeptides via bacterial fermentation, U.S. Patent No. 5,342,763. Genentech, Inc., USA, 1994.

[36] H. Tersawa, D. Kodha, H. Hatanaka, K. Nagata, N. Higashihashi, H. Fujiwara, K. Sakano and F. Inagaki, Solution structure of human IGF-II; recognition sites for receptors and binding proteins, EMBO J. 13 (1994), 5590-5597.

[37] F.F. Vajdos, M. Ultsch, M.L. Schaffer, K.D. Deshayes, J. Liu, N.J. Skelton and A.M. de Vos, Crystal structure of human insulin-like growth factor-1: detergent binding inhibits binding protein interactions, Biochemistry 40 (2001), 1102211029.

[38] G.A. Weiss, C.K. Watanabe, A. Zhong, A. Goddard and S.S. Sidhu, Rapid mapping of protein functional epitopes by combinatorial alanine scanning, Proc. Natl. Acad. Sci. USA 97 (2000), 8950-8954.

[39] K. Wüthrich, NMR of Proteins and Nucleic Acids, Wiley, New York, 1986.

[40] W. Zeslawski, H.G. Beisel, M. Kamionka, W. Kalus, R.A. Engh, R. Huber and K.H. Lang, The interaction of IGF-I with the N-terminal domains of IGFBP-5, EMBO J. 20 (2001), 3638-3644.

[41] C. Zwalen, P. Legault, S. Vincent, J. Greenblatt, R. Konrat and L. Kay, Methods for measurement of intermolecular NOEs by multinuclear NMR spectroscopy: application to a bacteriophage N-peptide/boxB RNA complex, J. Am. Chem. Soc. 119 (1997), 6711-6721. 


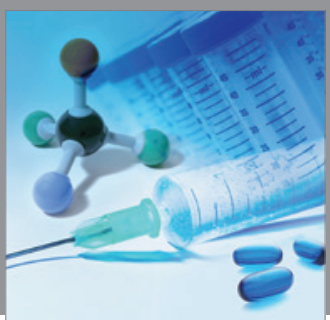

International Journal of

Medicinal Chemistry

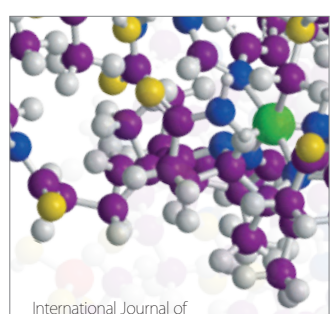

Carbohydrate Chemistry

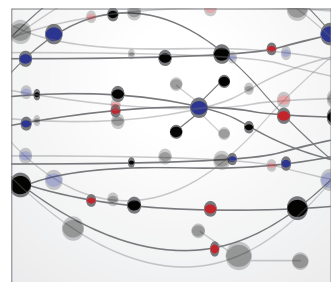

The Scientific World Journal
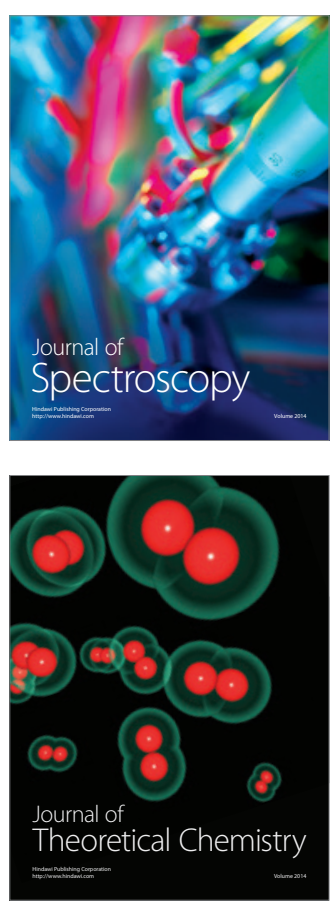
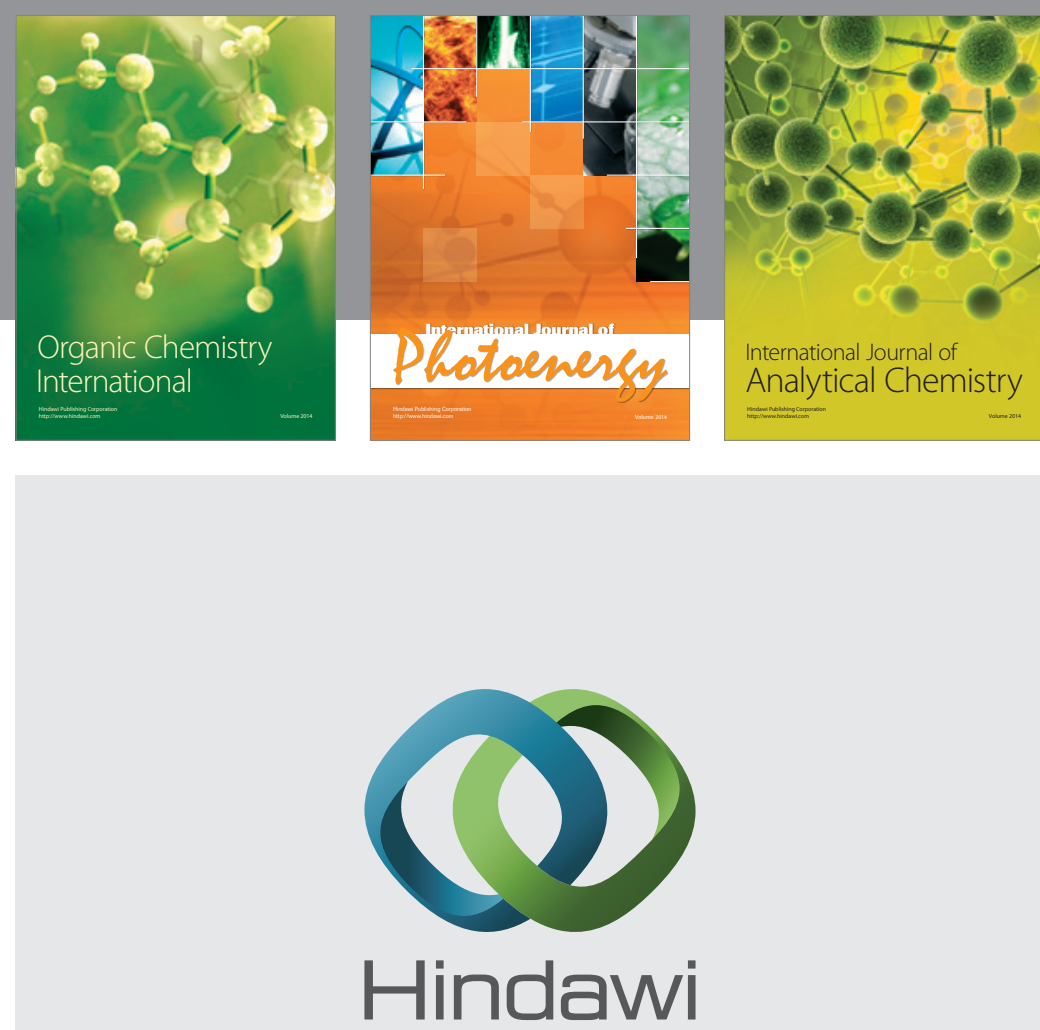

Submit your manuscripts at

http://www.hindawi.com
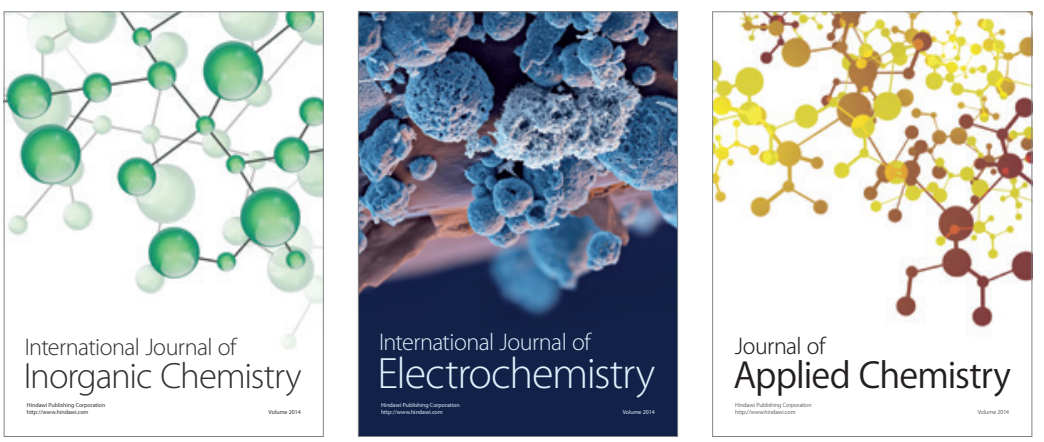

Journal of

Applied Chemistry
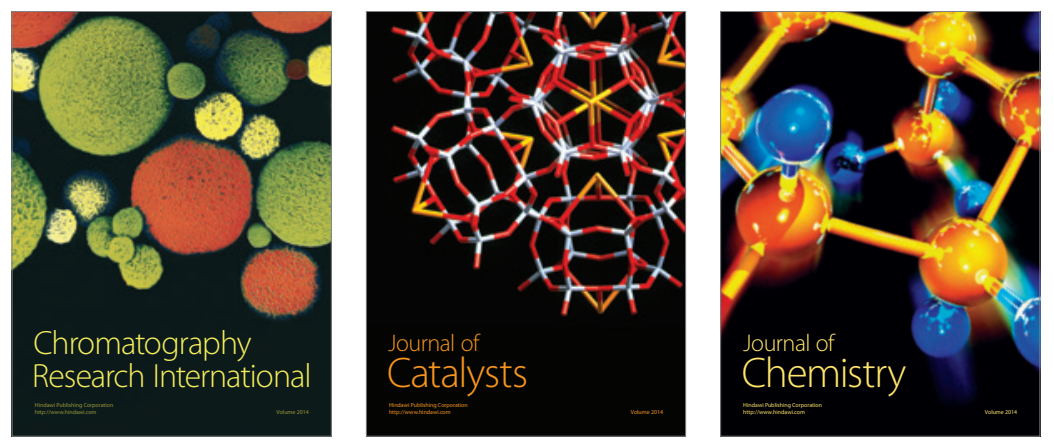
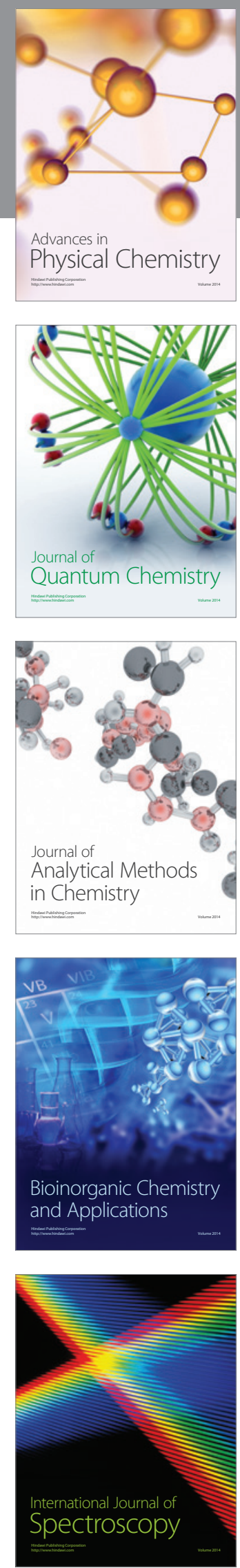